\title{
Un acercamiento a la arquitectura de Facebook a partir de los usos y apropiaciones de adolescentes de sectores populares de Buenos Aires*
}

\author{
Joaquín Linne ${ }^{1}$ \\ Universidad Nacional de Lanús, Universidad de Buenos Aires, Consejo Nacional de \\ Investigaciones Científicas y Técnicas (Argentina)
}

Recibido: junio 18 de 2015 - Revisado: agosto 24 de 2015 - Aceptado: septiembre 28 de 2015

Referencia formato APA: Linne, J. (2015). Un acercamiento a la arquitectura de Facebook a partir de los usos y apropiaciones de adolescentes de sectores populares de Buenos Aires. Revista Cientifica Guillermo de Ockham, 13(2), 65-75.

\section{Resumen}

El presente artículo aborda los usos y las apropiaciones de Facebook que hacen los adolescentes de sectores populares de la ciudad de Buenos Aires. A partir de la descripción de las diez funciones principales de la plataforma, se brindan ejemplos y análisis sobre cómo esta población utiliza el sitio. La metodología consiste en observaciones copresenciales y virtuales junto con veinte entrevistas en profundidad. Entre los resultados, se destaca que los adolescentes referidos despliegan un uso estratégico de la plataforma para autopresentarse y construir, mediante performances de intimidad, una identidad personal para su perfil en la red. Al compartir contenidos personales, principalmente con sus amistades cercanas, despliegan una autobiografía en su perfil online a través de la práctica cotidiana de registrar tanto sus relaciones significativas como sus consumos culturales. A su vez, se sostiene que los adolescentes contemporáneos representan una "generación post-mail" que centra una gran parte de su actividad online en la plataforma Facebook. Por último, se evidencia que la mayoría de los adolescentes observados se reapropian de los elementos que provee la arquitectura de Facebook para desarrollar su identidad online, y que dicha destreza resulta de la experiencia común de utilizar la red social.

Palabras clave: Adolescentes, sectores populares, sitios de redes sociales, Facebook, identidad

\section{An approach to architecture from Facebook applications and appropriations of teenagers popular sectors of Buenos Aires}

\section{Abstract}

This article discusses the uses and appropriations of Facebook which teens perform in popular sectors of Buenos Aires. From the description of the ten main functions of the platform, examples and analysis on how this population uses

\footnotetext{
* El presente artículo es producto de la tesis doctoral del autor, aprobada por la Universidad de Buenos Aires a inicios de 2015. La tesis aborda los modos como los adolescentes de sectores populares de Buenos Aires se presentan, mantienen relaciones de amistad y se vinculan sexoafectivamente mediante el sitio de redes sociales Facebook. La perspectiva teórica elegida es cualitativa-interpretativa y se inscribe en una intersección entre los campos de la sociología de la cultura y los estudios de comunicación.

1. Doctor en ciencias sociales, magíster en comunicación y cultura, sociólogo y docente de la Universidad de Buenos Aires. Es investigador del Consejo Nacional de Investigaciones Científicas y Técnicas (Conicet), con sede de trabajo en el Instituto de Investigaciones Gino Germani. E-mail: joaquinlinne@gmail.com
} 
the site is provided. The methodology consists of co-presencial and digital observations together with 20 in-depth interviews. Among the results it was highlighted that adolescents deployed strategic uses of the platform for selfpresentation and building a personal identity for their online profiles through performances of intimacy. By sharing personal content, especially with their close friends, they display an autobiography on their online profile through the daily practice of registering both their significant relationships as well as their cultural consumption. In turn, it argues that contemporary adolescents represent a "post-mail generation" that focuses most of their online activity on Facebook. Finally, it appears that the majority of teenagers observed were re-appropriated of the elements that the architecture of FB provides to develop their online identity, and that this skill is a result of the common experience of using the social network.

Keywords: Adolescents, popular sectors, social networking sites, Facebook, identity

\section{Uma abordagem para a arquitetura de aplicativos do Facebook e dotações de adolescentes setores populares de Buenos Aires}

\section{Resumo}

Este artigo discute os usos e apropriaçóes de adolescentes Facebook realizando setores populares de Buenos Aires. A partir da descrição dos dez principais funçôes da plataforma, exemplos e análise de como esta população utiliza o local é fornecida. A metodologia consiste em copresenciales e observaçôes virtuais juntamente com 20 entrevistas. Entre os resultados destacou que esses adolescentes implantado uso estratégico da plataforma para autopresentarse e construir uma identidade pessoal para o seu perfil na web, através de performances de privacidade. Ao compartilhar conteúdo pessoal, especialmente com seus amigos mais próximos, eles exibem uma autobiografia em seu perfil on-line através da prática diária de registrar ambos os seus relacionamentos significativos como o consumo cultural. Por sua vez, argumenta que os adolescentes contemporâneos representam uma "geração pós-mail" que se concentra grande parte de sua atividade on-line na plataforma Facebook. Finalmente, parece que a maioria dos adolescentes observados elementos reapropriar que FB fornece a arquitetura para desenvolver a sua identidade on-line, e que esta habilidade é a experiência comum de uso da rede social.

Palavras-chave: Adolescente, setores populares, sites de redes sociais, Facebook, identidade

\section{Introducción}

La importancia de las tecnologías de la información y la comunicación (TIC) en la vida cotidiana de la mayoría de las personas se ha vuelto un dato insoslayable para los estudiosos de las ciencias sociales y la comunicación. A nivel global, en el 2013 Facebook alcanzó los 1.230 millones de usuarios (Internet World Stats, 2014), lo que indica su preponderancia entre los sitios de redes sociales. En la Argentina, un reciente relevamiento efectuado a 3.600 personas mayores de doce años distribuidas en los principales centros urbanos, revela que hay un $71 \%$ de usuarios de computadoras (Sistema de Información Cultural de la Argentina, 2014). La mencionada investigación, postula que la actividad principal es el uso de sitios de redes sociales, entre los cuales Facebook se destaca con el $55 \%$. Estos datos señalan la importancia de esta red social como plataforma preferida por los usuarios para desplegar la mayoría de sus actividades online.

Uno de los grandes méritos de Facebook ha sido adoptar los aportes más significativos de otros sitios de redes sociales. En primer lugar, la creación de perfiles personales articulados con la visibilización de listas de contactos de redes como Friendster. En segundo lugar, el photo sharing ${ }^{2}$ de redes como Flickr. En tercer lugar, el video sharing de Youtube. En cuarto lugar, el breve comentario online y en red propio de Twitter (López \& Ciuffoli, 2012). Además, Facebook llamó "amigos" a los contactos e integró chat, juegos, imágenes y otras aplicaciones.

2. Por sharing se entiende compartir o intercambiar fotos (photo sharing) o videos (video sharing). 
De este modo, la red se ha convertido en la puerta de entrada a internet para millones de personas, en especial para adolescentes (Urresti, 2012; Linne, 2014). Esto se explica, en parte, por su capacidad para conjugar la interacción textual, la estética-visual y los elementos indiciales, como las fotos, los emoticones, las funciones de etiquetado y los "me gusta" (MG), ${ }^{3}$ que configuran este espacio virtual y presencial, público y privado (López $\&$ Ciuffoli, 2012). En este sentido, se suma a las plataformas de internet más exitosas, que son aquellas que permiten involucrar un mayor nivel de corporalidad. Además, Facebook es el principal sitio en el que se integran edades, disponibilidades temporales, recursos socioeconómicos, alfabetizaciones y situaciones cognitivas diferentes (López \& Ciuffoli, 2012; Linne, 2014).

Al comienzo de la investigación, se volvió evidente que Facebook era $-y$ sigue siendo- la plataforma preferida de los adolescentes de sectores populares de la ciudad de Buenos Aires. En una de las primeras entrevistas, un adolescente dijo: "para nosotros, internet es Facebook", en alusión a que allí pasan la mayor parte del tiempo conectados, lo que justifica su elección como entorno analítico (Linne, 2014). Si Facebook se ha vuelto este centro multioperativo de los adolescentes, es preciso entender mejor su funcionamiento. En este sentido, se analiza la arquitectura de esta plataforma semipública, ${ }^{4}$ según los usos y apropiaciones que los propios adolescentes hacen de ella.

\section{Método}

Para este artículo, se llevaron a cabo observaciones copresenciales, además de veinte entrevistas en profundidad a adolescentes de sectores populares, durante el año 2014. Tanto las entrevistas como las observaciones se hicieron en colegios, centros de inclusión digital, cibercafés y vía pública. Para establecer el número necesario de observaciones y entrevistas de la muestra intencional, se recurrió al criterio de saturación de la información.

El trabajo de campo ha sido complementado con una etnografía digital efectuada en Facebook, a partir de la creación y mantenimiento de un perfil ad-hoc en la plataforma, que en la actualidad cuenta con 2.947 contactos, en su mayoría pertenecientes a la población de estudio. La herramienta descrita para desarrollar la etnografía virtual, permitió observar la interacción de los adolescentes con sus contactos significativos dentro de la red social. La elección de este tipo de etnografía resultó la más conveniente en esta instancia de investigación, en la que el foco de análisis apunta a la construcción identitaria online, así como a los vínculos de amistad y sexoafectividad desplegados por estos adolescentes. Como señala Boyd (2008), "Facebook se volvió el sitio dominante de mi trabajo de campo simplemente porque este sitio domina la atención de los adolescentes” (p. 75).

Se han tomado recaudos para proteger la identidad de los adolescentes que conforman la muestra. En primer lugar, no se utilizan nombres ni datos personales que permitan su localización. En segundo lugar, se han difuminado -con programas de edición digital- los rostros en todas las imágenes, lo que le da al material tomado como evidencia un carácter anónimo y evita la identificación personal. A su vez, en el caso de las entrevistas y observaciones copresenciales, se cuenta con autorización expresa de los participantes. En definitiva, se subraya que la presente investigación tiene fines estrictamente científicos, razón por la cual se evitan las posibles identificaciones de los usuarios referenciados.

\section{Estado del arte}

En primer lugar, en esta investigación se utiliza el "enfoque dramatúrgico" (Goffman, 1959), que propone analizar de modo cualitativo las estrategias a través de las cuales las personas se presentan ante los otros. Según el planteamiento de Goffman (1959), los individuos recurren a "técnicas de manejo de las impresiones" para intentar ser eficaces y lograr sus objetivos. De este modo, la interacción puede ser pensada como una constante actuación teatral (performance), en la que se diferencian las prácticas realizadas en el "frente del escenario" (front stage) de las que transcurren "atrás del escenario" (back stage). Lejos del front, las acciones pueden ser corregidas, editadas o ensayadas. De este modo, a través de metáforas teatrales, Goffman (1959) argumenta que la identidad de los individuos es el producto social de las performances que efectúan en distintas situaciones. Si bien este argumento es anterior a la masificación de las TIC, resulta útil para analizar la interacción en sitios de redes sociales. Tal como seńala Farquhar (2009), la mayoría de las actividades de

3. La contracción MG es una categoría nativa de los adolescentes.

4. El espacio de Facebook es definido aquí como semipúblico, dado que no es ni público -como una plaza o escuela pública- ni privado -como un inmueble o un sitio pago-. Este espacio virtual gratuito puede ser utilizado por cualquiera. A su vez, lo que publican los usuarios es público, en el sentido de que cualquiera accede a esas publicaciones, pero también es posible de ser privado, al aplicar restricciones en la configuración del perfil propio, de modo que la información y las publicaciones personales sean visibles solo para los contactos o para ciertos contactos seleccionados. 
los usuarios en Facebook forman parte de su front, salvo las que se hacen offline y consisten en configurar la cuenta y editar la lista de contactos, que constituirían el backstage de las performances desplegadas en la plataforma.

A nivel local, este artículo continúa la línea de Urresti (2008; 2012), quien señala que las "ciberculturas juveniles" implican nuevas formas de creación y sostenimiento de comunidades afectivas a través de sitios de redes sociales, que son al mismo tiempo inclusivas y excluyentes.

Las ciberculturas aluden a un proceso de múltiples convergencias entre las esferas de la vida cotidiana de los actores y el cúmulo de tecnologías digitales que las atraviesan cada vez más densa y persistentemente, situando en un terreno nuevo la interacción [...] Las generaciones más jóvenes desarrollan su experiencia primera en estas coordenadas, tomando este estado particular de la evolución de la sociedad y la cultura como el mundo que les tocó vivir (Urresti, 2012, p. 22).

Según López y Ciuffoli (2012), una de las claves Facebook es su destreza para bajar constantemente las barreras cognitivas. La hipótesis es que esta red democratiza la internet como espacio de subjetivación al permitir que quienes antes no participaban en la web comiencen a hacerlo. Para estas autoras, Facebook es claro en sus propuestas y promesas: comunicarse, entretenerse e "informarse" con amigos y conocidos a través de las publicaciones personales.

A nivel internacional, se recupera de Boyd y Ellison (2007) su categorización de sitios de redes sociales. Estas autoras despliegan un pormenorizado racconto de la historia y características principales de estas plataformas. Entre sus principales resultados, señalan que tornan visibles las redes de contactos y amistades preexistentes.

Respecto a la configuración del perfil en Facebook , Farquhar (2009) señala que los usuarios tienden a buscar aceptación social a través de sus presentaciones y, en parte por esto, construyen sobresimplificadas versiones de sí mismos para reducir la ambigüedad y alinearse con grupos sociales específicos. A su vez, Pedroni, Pasquali y Carlo (2014) señalan, a partir de una muestra de jóvenes y adultos italianos, que los usuarios de Facebook suelen considerar a sus amigos como su audiencia, y que para esto seleccionan los aspectos del front (Goffman, 1959) de su perfil que desean mostrar ante los demás. Sin embargo, la interacción cotidiana de los adolescentes con la plata- forma ocasiona distintas tensiones y conflictos. En este sentido, si bien sus "comunidades personales" les ayudan a desarrollar su identidad (Boyd, 2014), también pueden reforzar problemáticas de género y de clase.

En línea con estas investigaciones, se aporta evidencia empírica acerca de que el uso frecuente de Facebook aumenta el capital social de sus usuarios. Pero este capital no aumenta per se-solo por "estar conectados"-sino porque Facebook provee un ecosistema mediático en donde se vuelve más fácil el intercambio fluido de estrategias que permiten consolidar ciertas relaciones y, por ende, aumentar el capital social.

Por último, cabe aclarar que mientras que la utilización contemporánea del concepto "nativos digitales" (Prensky, 2001) homogeniza a la generación de adolescentes e invisibiliza sus diferencias (Van Dijk, 2013), este artículo pretende cubrir un área de relativa vacancia en el estado del arte: las apropiaciones específicas de Facebook que hacen los adolescentes de sectores populares. Como se ha señalado, esta red social tiene mayor éxito entre los adolescentes en general, que necesitan del constante feedback ${ }^{5}$ de sus pares acerca de su identidad y sus performances, $y$ en especial, entre quienes poseen dificultades en su escolarización, tal como ocurre en los sectores populares de la ciudad de Buenos Aires. Por todo ello, es importante conocer los modos de socialización en sectores populares y cómo estos se despliegan en Facebook, de acuerdo con su arquitectura específica.

\section{Desarrollo}

Con el fin de ilustrar y contextualizar los principales elementos y funciones de Facebook, se presentan diez ítems: 1. cuenta de Facebook; 2. perfil y muro; 3. biografía; 4. columna de noticias; 5 . lista de amigos; 6 . MG y comentarios; 7. casilla de mensajes y chat; 8 . actualizaciones de estado; 9. aplicaciones, y 10. etiquetado. De cada uno, se ofrece una descripción junto con un breve análisis y ejemplos extraídos del trabajo de campo. Este acercamiento a la estructura del sitio junto con las apropiaciones que llevan a cabo los adolescentes de sectores populares de la ciudad de Buenos Aires, resulta de utilidad para avanzar en la comprensión del fenómeno de masividad que tiene la plataforma en esta población.

5. Término en inglés -sin traducción exacta en espańol- que refiere a la medición de un contenido o performance según la devolución o respuesta de los otros. Los comentarios o MG que reciben, por ejemplo, una foto de portada o una publicación se denominan feedback. 


\section{Cuenta de Facebook ${ }^{6}$ (Facebook account)}

Es lo primero que una persona necesita para participar de la plataforma. Para crear una cuenta, debe ingresar obligatoriamente un nombre (nickname) y un correo electrónico válido para confirmar su identidad. De manera opcional, puede agregar foto de portada y perfil, teléfono, ciudad de residencia, barrio, ocupaciones actuales y anteriores (estudios, trabajos), estado civil, intereses y actividades frecuentes (hobbies). A través del buscador interno, el usuario puede rastrear a conocidos que ya son parte de Facebook y enviarles solicitudes de amistad. Como se verá, el nombre del usuario -único dato obligatorio de la cuenta- es el principio de la configuración de la autopresentación en Facebook y evidencia los estilos elegidos a partir de los recursos disponibles en cada sector social. En el caso de los adolescentes de sectores populares de la ciudad de Buenos Aires, desde el inicio de la configuración de la cuenta suelen resaltar su pertenencia barrial (por ejemplo, "Mtd", contracción del barrio de Mataderos), la adhesión a un equipo de fútbol ("Club Atlético Nueva Chicago", representativo de la zona sur de la ciudad) y su identidad social a partir de mostrarse solos o acompańados, junto a sus pares íntimos, su pareja o su familia. Una particularidad en sectores populares es que los adolescentes suelen ponerse un nombre de fantasía (por ejemplo, Brisa) o apodo (Alee) junto a la especificación barrial (Brisa Mtd). Esta estrategia no solo da cuenta del sentido de pertenencia social de estos adolescentes, sino que también facilita la búsqueda de contactos afines a partir del territorio.

\section{Perfil (profile) y muro (wall)}

Hasta el 2012, estas eran las dos secciones básicas de Facebook: el perfil contenía los datos personales y el muro era el espacio de interacción cotidiana. Si bien estas funciones fueron reemplazadas por la "biografía", todavía muchos usuarios - y hasta la misma plataformasiguen llamándolas "perfil" y "muro", en parte porque dan cuenta con mayor precisión de sus singularidades: en el primer caso, la de ser el espacio en el que se diseńa un "perfil" de usuario y, en el segundo, la sección en la que se hacen inscripciones para ser vistas por quienes visitan el "muro". En el servicio de ayuda, Facebook recomienda que el "perfil debe ser como tu casa en internet". Tanto el perfil como la foto de portada y las interacciones que se efectúan en el "muro" pueden ser definidas como el front (Goffman, 1959) de cada usuario.
En este sentido, en los últimos años el sitio puso más énfasis en que cada usuario tenga mayor conciencia de la información que presenta, facilitando así la edición y las opciones de accesibilidad de los contenidos personales. A mediados de 2014, Facebook lanzó una aplicación para revisar la configuración de privacidad de los contenidos publicados. Con esta innovación, el sitio busca neutralizar las críticas en torno a esta problemática. Desde el enfoque dramatúrgico que propone Goffman, se puede afirmar que se dio más lugar al backstage para tener mayor control sobre las publicaciones.

En el trabajo de campo se observó que entre los adolescentes de sectores populares las "firmas de muro" (comentarios públicos al perfil del usuario) dan cuenta de cierto reconocimiento hacia el destinatario, quien es valorado por haber logrado dicho feedback en la red. En el caso de los varones, también se asocia a "ganador" o "exitoso" respecto a su capacidad de seducción a pares mujeres. Este horizonte regulativo relativamente nítido entre los varones opera de modos más contradictorios entre las mujeres, quienes son visiblemente más cuestionadas si aparecen entre sus contactos como "exitosas" en un sentido sexoafectivo.

\section{Biografía (timeline o línea de tiempo)}

En el 2012, esta nueva función integró el muro y el perfil en una sola página. La biografía es la sección en la que el usuario comparte y edita su información personal y su actividad reciente. Aquí pueden agregarse fotos, destacar imágenes o publicaciones, actualizar el estado, añadir eventos y compartir la actividad generada en aplicaciones. A diferencia del perfil y el muro, la biografía se destaca por ser más visual y abarcativa. Esta función almacena y jerarquiza la actividad de cada usuario, resaltando de esta manera los hitos vitales como cumpleaños, casamientos y otros hechos cruciales. Asimismo, divide las actividades cronológicamente por años, señala la antigüedad del usuario en la plataforma y, opcionalmente, su fecha de nacimiento. También provee información sobre la fecha exacta de publicaciones, actualizaciones de estado y comentarios. Junto con la biografía, también se agregó la foto de portada, que figura en la parte superior de la página personal y no puede ocultarse. La "biografía" enfatiza el sentido cronológico de la actividad, al tiempo que ordena los datos y acciones del usuario, como, por ejemplo, el estado sentimental, la lista de amigos, las páginas preferidas, la pertenencia a grupos y los juegos utilizados.

6. Junto al nombre en español del elemento o función, figura entre paréntesis el nombre original en inglés. Esta aclaración es de utilidad porque en ocasiones los adolescentes utilizan la denominación original, como en el caso de inbox, like, comment o app.

7. Facebook aclara en su información de ayuda que "biografía" y "perfil" se utilizan de modo indistinto. 
Cuando un usuario configura su cuenta (aspecto básico de su front), se le pide cierta información sobre sí mismo y dos imágenes personales denominadas fotos de perfil y portada: mientras la primera suele presentar al usuario en soledad, la segunda suele mostrarlo en compañía (pareja, amistades, grupos de pares y familiares). Al ingresar a una biografía ajena, lo primero que se ve es el nombre junto a las fotos de portada y perfil. De este modo, la foto de perfil funciona como un sello o ícono que acompaña al usuario en sus acciones de Facebook, mientras que el nombre es lo más parecido a una firma que se vuelve conocida entre sus contactos. Aunque un usuario sólo publique textos, Facebook publica su foto de perfil junto a su nombre en cada acción que hace. A su vez, un modo frecuente de generar actividad para que aparezca como noticia en la biografía es cambiar la foto de portada o perfil. Por todo esto, es posible afirmar que las imágenes son centrales en la arquitectura de Facebook (Linne, 2014).

Uno de los aspectos centrales del front es la información personal, que consiste en los datos que pide completar para que figuren después del nombre y las fotos de portada y perfil. Esta información aparece a la izquierda en la página de biografía del usuario. Los datos requeridos, que pueden completar de modo opcional, son los siguientes: barrio, ciudad, "estado sentimental", estudios, trabajo y seguidores.

Bajo esta información básica, figuran las fotos y amigos que han tenido mayor actividad con la cuenta, cuántos contactos y fotos tiene el usuario y el número de amigos en común. En conjunto, estos ítems funcionan como indicadores de afinidad y confianza. En este sentido, solo contactos que resultan atractivos, o con quienes tiene cierta cantidad de "amigos en común" suelen calificar para ser aceptados o para proponer mayores interacciones.

\section{Entrevista}

Si tenemos muchos amigos en común, lo acepto. Si no tenemos ninguno, no lo acepto, porque puede ser cualquiera: un violador, un mentiroso, un ladrón. Solo acepto conocidos o con los que tengo muchos contactos en común (mujer, 17 años, sectores populares).

Se ha observado una apropiación singular por parte de estos adolescentes respecto a los ítems de información básica. Por ejemplo, en "trabajo" muchos ponen "rey de la vagancia" o "en la cama con tu novio". Estas respuestas personales a exigencias de Facebook evidencian creatividad y humor, además de una forma de resistencia social.
Bajo los datos de información personal, suelen aparecer las preferencias del usuario, formadas a partir de las páginas a las que se indicó MG. Entre otros, figuran los ítems "lugares", seguido de "deportes", "música", "aplicaciones", "juegos", "grupos", "páginas" y "actividad reciente". En configuración, el usuario puede elegir qué mostrar en su biografía.

\section{Entrevista}

Algunas cosas que publico solo las ven mis mejores amigos. Otras las dejo públicas para que las vean todos. Pero lo que tiene que ver con salidas y cosas más personales lo cerramos a un grupo para que no haya problemas. Solo las fotos de portada y perfil son siempre públicas, así que hay que tener más cuidado con esas (varón, 15 ańos, sectores populares).

De este modo, mientras unos presentan todas las opciones por default, otros solo exhiben sus preferencias deportivas y musicales, o "el estado sentimental" y los amigos. Esto forma parte de la autobiografía que construyen en el sitio; a través de la práctica cotidiana de hacer "performances de intimidad" (Linne, 2014) escenifican cierta identidad personal.

\section{Columna de noticias (news feed o proveedor de noticias)}

El muro fue reemplazado por esta función en 2012. Es la columna central de la página de inicio, conformada por una lista de las publicaciones y acciones de los contactos. A través de esta columna, Facebook renueva constantemente los contenidos generados por los usuarios. En esta sección se incluyen actualizaciones de estado y publicaciones. Ofrece, con una rápida mirada, un recorrido o paneo por los principales eventos de la red de contactos. A su vez, permite que siempre que un usuario ingrese a Facebook se encuentre con una muestra de las nuevas actualizaciones y eventos en su columna de noticias. Para los adolescentes de sectores populares, los usuarios más conocidos de modo copresencial y los usuarios más activos en la plataforma suelen representar la base de la sociabilidad en Facebook y son quienes más enriquecen la columna de noticias de un perfil.

Se observa que desarrollar un perfil activo brinda prestigio entre los adolescentes, aunque también genere conflictos de celos, competencia y envidia con distintos usuarios y contactos de la red. Es frecuente que los amigos menos fotografiados, publicados o invitados de un perfil "popular" sientan celos y reclamen ser invitados a eventos significativos y tener más protagonismo en las publicaciones mencionadas. 


\section{Entrevista}

Subí cinco fotos de un cumpleaños el año pasado y me protestaron muchos: "che, estaría bueno que festejés también con nosotros". Se armó una discusión de "no te invité a mi cumpleaños", que es una cosa que suele pasar desapercibida. Me pasaron a buscar, salimos, me sacaron cinco fotos, las subieron y se armó un quilombo. Éramos diez. Y se armó una discusión de "fuiste y nosotros no estábamos", no le veía el sentido (mujer, 17 años, sectores populares).

\section{Lista de amigos (friends list)}

Aquí son agregados los contactos, a quienes se denomina "amigos". Para formar parte de esta lista, es preciso que un contacto envíe una solicitud de amistad y que el destinatario la acepte. El máximo permitido que puede alcanzarse es de 5.000 contactos. En Facebook se pueden localizar y enviar solicitudes a antiguos conocidos o buscar nuevos contactos. Para ello, se provee un buscador y una herramienta que sugiere constantemente amigos, con el fin de promover de modo cotidiano el flujo de actividad.

Por otra parte, Facebook penaliza a quienes envían solicitudes de amistad a desconocidos. Si el usuario continúa con ese comportamiento, se bloquea esa función por un tiempo determinado (por ejemplo, catorce días). Este mecanismo basal de la plataforma es uno de los aspectos más conflictivos, en especial para los adolescentes que se encuentran en plena configuración de su identidad. Por ejemplo, un adolescente (diecisiete años, sectores populares) avisa en su actualización de estado que "cuatro días más y me desbloquean las solis" (solicitudes) y sus amigos lo acusan de haber querido agregar a demasiadas mujeres desconocidas.

Es frecuente que los adolescentes de la muestra se quejen de que Facebook les bloquea momentáneamente las solicitudes de amistad. La tendencia a querer aumentar la cantidad de amigos de modo constante se explica, en parte, porque es muy fácil, adictivo y da "estatus" tener muchos contactos. Además, la mayor cantidad de contactos aumenta la posibilidad de ver perfiles, de recibir MG y, en menor medida, comentarios. El intercambio "silencioso" de MG suele ser señal de afinidad, estima o atracción y puede devenir en un chat que, en ocasiones, deriva en un mayor vínculo virtual y, a posteriori, en encuentros copresenciales.

A su vez, Facebook estimula la interacción de modo constante, proponiendo juegos y páginas ("Páginas/Juegos que podrían interesarte"), pero en especial sugiriendo nuevos contactos a través de la función "personas que quizás conozcas". Este servicio, que funciona por default en toda cuenta, busca aumentar el número de contactos a partir de unir a usuarios que comparten instituciones, barrios y "amigos". A mayor densidad de círculos superpuestos -cantidad de amigos en común, según la denominación de Facebook-, la red se fortalece. En este sentido, su crecimiento en los últimos años se relaciona estrechamente con la inicial confluencia y posterior integración que supo establecer entre amigos y contactos (López \& Ciuffoli, 2012), multimedia e imágenes personales.

\section{"Me gusta" (like) y comentarios (comments)}

Ante cada publicación de un contacto, es posible poner MG o dejar un comentario. El MG figura en la parte inferior de cada publicación. Este icono tiene forma de una mano con el pulgar hacia arriba. Cumple una doble función: por un lado, sirve para dar muestras de satisfacción ante publicaciones propias y ajenas; por otro, para medir el feedback y el nivel de satisfacción que obtiene una publicación. Es el icono más famoso de Facebook, con el que se lo reconoce internacionalmente tanto dentro como fuera de internet. Por ser una de las funciones más utilizadas, es común que el MG sea el primer signo de acercamiento entre usuarios.

Muchos adolescentes de sectores populares limitan su participación en el sitio a dar MG en algunas publicaciones que les agradan. Otros se apropian de esta función como "moneda de cambio". Por ejemplo, intercambian un MG por un saludo, un dato o un comentario en la biografía. De este modo, los adolescentes intercambian MG mientras visitan perfiles ajenos de modo voyerístico. Esta acción permite ampliar los recursos para sumar "popularidad" y buscar relaciones. Una gran parte de las estrategias que despliegan los adolescentes de sectores populares para ampliar la sociabilidad son dirigidas a la exploración de posibles contactos sexoafectivos. Para extender su radio de interacciones en el sitio, por ejemplo, prometen una lista de "los quince más lindos y partibles" de su Facebook o dar el número telefónico por un MG. La siguiente publicación tiene $74 \mathrm{MG}$ (signo de alta aceptación) y pertenece a un varón (dieciséis años, sectores populares) que propone intercambiar un MG por un comentario ("firma") en el muro.

Por su parte, los comentarios también sirven para medir el feedback que obtiene una publicación. Al igual que con los MG, una publicación se considera "exitosa" si obtiene decenas de comentarios. Facebook "premia" este alto nivel de feedback dándole un lugar preponderante en las columnas de noticias de sus contactos, lo que colabora para seguir aumentando su nivel de MG y comentarios. 
Dado que Facebook no explicita los mecanismos que utiliza para darles más prioridad a algunas publicaciones que a otras, el razonamiento que se instala entre los adolescentes surge de los elementos en común que se observan entre las publicaciones más vistas: decenas o cientos de MG y comentarios. De acuerdo con esta lógica, miles de usuarios -en especial, adolescentes- desean ampliar continuamente su número de contactos para conseguir tener visibilidad entre las columnas de noticias de su red de amigos. A su vez, tener miles de contactos en Facebook es signo de estatus y de ser un usuario experimentado y valorado dentro del sitio.

En sectores populares, los adolescentes escriben estos comentarios con alto grado de "oralidad": con mayúsculas, sin respetar en gran parte las reglas ortográficas tradicionales. Muchas veces escriben sin comas y sin acentos, usando la repetición de letras para enfatizar sus publicaciones. ${ }^{8}$ Por ejemplo, "quiiieeennn me FIRMAA, le comento la foto de perfil al que firma” (mujer, dieciséis años, sectores populares), con relación a que proponen intercambiar un comentario en el muro por un comentario de la foto de perfil.

\section{Casilla de mensajes (inbox) y chat}

Mientras que el inbox permite intercambiar mensajes privados diacrónicos, ${ }^{9}$ el chat consiste en el intercambio de mensajes privados sincrónicos. ${ }^{10}$ Para la generación contemporánea de adolescentes la casilla de mensajes de Facebook en gran medida ha reemplazado al tradicional email, por lo que puede denominarse generación post-mail (Linne, 2014).

\section{Entrevista}

Me saqué un mail para entrar a Facebook pero nunca lo usé. No le encuentro utilidad, y ninguno de mis amigos lo usa. Todos nos comunicamos por Facebook y Whatsapp. Es lo más cómodo y rápido y lo que usan todos. Si no tenés Whatsapp o Twitter, bueno, pero los que no tienen Facebook viven en otra galaxia (varón, 14 años, SM).

Nunca necesité usar mail ni me interesa. Solo saqué uno porque me lo pedía Face para entrar. No lo entiendo y me parece de viejos. En el taller de computación el profesor nos dijo de sacar uno, pero le dijimos que era mejor comunicar- nos por Facebook, que ahí ya estábamos todos (mujer, 18 años, sectores populares).

Los adolescentes de sectores populares suelen comunicarse con sus amigos, familiares y compañeros de escuela a través de sitios de redes sociales como Facebook y programas de mensajería instantánea como Whatsapp. El mail simplemente no les resulta funcional, a diferencia de la generación anterior, para quien el correo electrónico es -o al menos ha sido hasta hace poco tiempo- una herramienta fundamental.

En cuanto al chat, este servicio de mensajería instantánea es utilizado tanto entre amigos copresenciales como entre contactos desconocidos. Implica un grado mayor de intimidad que la interacción a través del muro o las publicaciones. Junto a cada contacto que se encuentra online, el sitio aclara si está conectado desde la web o desde su teléfono móvil. Una significativa parte de los hogares de sectores populares de la ciudad de Buenos Aires carece de conectividad hogareña, aunque sí poseen acceso a Internet wifi a través de sus respectivos teléfonos celulares, por lo que la mayoría de adolescentes de sectores populares chatea a través del teléfono celular.

A través del chat, los adolescentes de sectores populares mantienen relaciones significativas con pares y en algunos casos intensifican vínculos. Según las entrevistas y observaciones, la mayor parte del tiempo se comunican con amistades cercanas, compañeros del colegio y familiares. Esto convive con una búsqueda de experimentación sexoafectiva, que para la mayoría se reduce a dejar que otros vean su perfil, a mirar perfiles ajenos y a dar MG. Solo los más osados chatean de modo frecuente con desconocidos. No obstante, la mayor parte del tiempo chatean entre el círculo de amigos íntimos. A su vez, los temas de conversación en el chat entre los adolescentes de sectores populares son las relaciones sexoafectivas, las relaciones de amistad, el colegio y la familia. En particular, chatean sobre quién les gusta, rumores y publicaciones de compañeros de colegio, tareas escolares, conflictos familiares, contactos atractivos de Facebook, consumos culturales y tecnología.

Por otra parte, al igual que con los mensajes privados, Facebook guarda un registro de los chats, lo que permite

8. Aclaración: el análisis sociolingüístico excede el marco de esta investigación. No obstante, el presente artículo indaga las maneras divergentes de construir sentido y producir subjetividad que tienen los sectores populares a partir de la masificación de estas herramientas comunicativas. Como se observa, la escritura de los adolescentes de sectores populares de la ciudad de Buenos Aires da cuenta de apropiaciones lectoescriturales divergentes a las que propone el sistema formal de educación. En cambio, los adolescentes de sectores medios suelen escribir de modo más similar al del sistema formal de educación y, a su vez, al de los adultos que reproducen el idioma oficial de las instituciones.

9. Con diacrónico se refiere a que los usuarios pueden estar en Facebook en distintos momentos para intercambiar mensajes.

10. Con sincrónico se refiere a que los usuarios deben estar conectados (online) al mismo tiempo en el sitio

$72<$ Universidad de San Buenaventura, Cali - Colombia 
un mayor monitoreo por parte de cualquiera que pueda "loguearse"11 en una cuenta ajena. Si un usuario no se "desloguea" al dejar de usar el dispositivo, otro usuario que ingrese al mismo sitio desde ese dispositivo puede utilizar esa cuenta. Estos conflictos en torno a la intromisión en cuentas ajenas se acentúan entre adolescentes de sectores populares porque es común que compartan el dispositivo con otras personas.

\section{Actualizaciones de estado (update status)}

Se trata de micropublicaciones que se enmarcan en la lógica de la plataforma: al ingresar al sitio, el usuario se encuentra con la pregunta "¿qué estás pensando?". Las respuestas a esta pregunta se denominan "actualizaciones de estado" y generan un flujo de información acerca de los contactos que se "acumulan" en las biografías y columnas de noticias. Son frecuentes las actualizaciones de estado sobre pensamientos, momentos personales o actividades cotidianas. Muchas de estas publicaciones, tal como se ha comentado, muestran una específica apropiación de códigos de escritura, vinculados tanto a la arquitectura de Facebook como a sus contextos sociales específicos y a sus interacciones cotidianas. En numerosos ejemplos, puede observarse en las publicaciones de los adolescentes que escriben "Hola, MG y te firmo con un te quiero". Un comentario común ante este pedido de intercambio es "te arruiné el estado", en referencia a una frase o imagen "fuera de lugar" en la sección de comentarios que perjudica la publicación original. Este tipo de respuestas ejemplifican la creatividad de estos adolescentes al apropiarse de funciones generales de la plataforma.

\section{Aplicaciones (apps) y juegos (games)}

Con las aplicaciones, por ejemplo, se puede averiguar el horóscopo, enterarse del pronóstico del clima, ver quiénes son los mejores amigos, hacer encuestas, indagar aspectos de la personalidad y hacer preguntas a contactos de modo anónimo. Dentro de estas, los juegos son las aplicaciones más difundidas en Facebook y utilizadas por los adolescentes de la población de estudio.

\section{Entrevista}

Todos tienen un Pet Society que dejaron de usar cuando tenían nueve años. La mayoría de las personas que tengo entre mis contactos se hicieron usuarios para jugar al Pet. Es un perrito que tenés de mascota que se compra cosas para su casa. Es adictivo. Se crean Facebook falsos para pasarse créditos (varón, 14 años, sectores populares).

De juegos los que más me gustan son el Counter Strike, el Criminal Case y los de fútbol, el Winning Eleven y el FIFA. Y también juego un montón a los que aparecen por Face, que es más cómodo, como Candy Crush o esos de mafia, de cartas o de crear civilizaciones. Y además tus amigos te mandan la invitación para jugar, así que jugás con ellos cuando están conectados. Te pasan trucos o es un tema más para charlar (varón, 14 ańos, sectores populares).

Candy Crush, Criminal Case y Angry Birds, entre otros, poseen una arquitectura digital que se imbrica de modo efectivo con el código abierto de Facebook. Aparte de la fácil accesibilidad, en el caso de Candy Crush, cada vez que los usuarios ingresan al juego la interfaz les pregunta si quieren enviarles "vidas" o movimientos extra a sus amigos que también utilizan el juego, o si quieren invitar a amigos que aún no lo juegan. Además, al "quedarse sin vidas" es posible pedirles a los contactos y es necesario que tres usuarios te otorguen una "vida" para pasar de etapa. De no poseer amigos en Facebook o no querer esperar a que los amigos otorguen "vidas", es posible pagar con tarjeta de crédito o créditos del teléfono celular. Al mismo tiempo, en cada paso de nivel la aplicación muestra el lugar que uno ocupa en el mapa y en el escalafón de amigos. A su vez, se le pregunta al usuario si quiere compartir con sus contactos la noticia de que superó determinado nivel.

Tanto Criminal Case como Candy Crush operan bajo una "economía del don" (Linne, 2014): si bien no es necesario, sí es satisfactorio intercambiar vidas, herramientas y movimientos entre amigos. Al mismo tiempo, de modo "amigable" y predeterminado, el juego impone una constante competencia entre contactos. Estos juegos tienen la particularidad de ser fáciles, con intermitentes niveles de dificultad matizados por ayudas y estímulos motivacionales contra la frustración: tras unos segundos de inacción, el juego indica un movimiento posible. En el caso de Candy Crush, tiene un constante test que monitorea el grado de diversión del usuario. Tanto los adolescentes de sectores populares como los de sectores medios muestran un uso intensivo de estos juegos asociados a Facebook, que conviven con las consolas de videojuegos.

\section{Etiquetado (tagged)}

Consiste en la aplicación de etiquetas de otros usuarios sobre las fotos publicadas. De este modo, al pasar el

11. Los adolescentes utilizan la expresión "loguearse" como sinónimo de ingresar a su cuenta en Facebook. Es una españolización del original en inglés log in, que significa ingresar o conectarse a una terminal. Esta expresión suele leerse al ingresar a la página de Facebook. Como opuesto, los adolescentes utilizan "desloguearse" a partir del log out (desconectarse) que también figura entre las opciones de Facebook. 
puntero del mouse por las personas de la imagen, si están etiquetadas aparecen sus nombres. Cuando se etiqueta a alguien, se crea un enlace (link) a su perfil. Además de las imágenes, también puede etiquetarse a otro usuario al hacer una publicación, lo que genera enlaces a sus biografías. A su vez, al etiquetar a otro usuario, este es notificado. Esta función genera en ocasiones diversos conflictos por no consultar antes al etiquetado.

\section{Entrevista}

Alguna vez etiqueté a alguien que me dijo "desetiquetame". Pero tampoco etiquetaba a mansalva. En algún momento subía con más frecuencia y me dijeron "esta foto no me gusta cómo salí; sacala” (mujer, 17 años, sectores populares).

A mí varios me pidieron que los desetiquetara y que por favor no lo repitiera, justamente para evitar ese tipo de conflictos. Es cierto, es rebuchón. Descubrimos hace poco que, según la restricción del álbum, tenés acceso a esa foto o a todas las fotos del álbum. Entonces por eso decidí no etiquetar a nadie más salvo a dos o tres y no se etiqueta ninguna otra foto, para que no las puedan ver más. Por lo que es muy difícil que alguien que no esté acceda a esas fotos (varón, 18 años, sectores populares)

Como se observa en los fragmentos de entrevistas citados, los adolescentes aprenden de la experiencia de uso de la plataforma y de la interacción constante con los pares que forman parte de su red de contactos. De este modo, un acuerdo tácito entre muchos de estos adolescentes es que para etiquetar se debe consultar al otro, dado que la publicación aparecerá en ambas biografías.

\section{Conclusiones}

Debido a su facilidad de uso, Facebook genera adhesión en una gran parte de los nuevos usuarios de internet, que en muchos casos presentan dificultades alusivas a su escolarización. En este artículo se ha trazado una arquitectura analítica de Facebook a partir de los principales usos desarrollados por los adolescentes de sectores populares de la ciudad de Buenos Aires. Esta "generación postmail" centra una gran parte de su actividad online en la plataforma, dado que no solo es su sitio web preferido, sino que en numerosas ocasiones es casi el único sitio de internet que frecuentan. Se ha observado que existe un diálogo constante de los adolescentes con las opciones predeterminadas y las categorías de la plataforma que justifica haber analizado la arquitectura del sitio. Por ejemplo, forman parte de los códigos cotidianos de los adolescentes de sectores populares de la ciudad de Buenos Aires las expresiones "MG", "firma", "contra" y "rela", que aluden, respectivamente, a términos propios de Facebook: "me gusta", "comentario", "contraseña" (clave para entrar a la cuenta) y "en una relación" (opción predeterminada frecuentemente elegida para definir el "estado sentimental").

En Facebook, los adolescentes de sectores populares suelen compartir, principalmente con sus amistades cercanas, contenidos personales. Así despliegan una autobiografía en su perfil online a través de la práctica cotidiana de registrar tanto sus relaciones significativas como sus consumos culturales: juegos, programas de televisión, grupos musicales, actores, películas, series, marcas de vestimenta, electrónica o comida. De esta manera, van construyendo colectivamente los códigos de lo deseado y lo ignorado, lo festejado y lo rechazado.

Ha quedado demostrado que los adolescentes se reapropian de los elementos que provee la arquitectura de Facebook para desarrollar su identidad online. Esta destreza resulta de la experiencia y del aprendizaje compartido en el uso de la red social. En sus perfiles online, los adolescentes de sectores populares de la ciudad de Buenos Aires combinan referencias identitarias vinculadas al territorio, al club de fútbol, a los vínculos afectivos y a los consumos culturales. A su vez, también generan estrategias de resistencia al expresar su disconformidad con respecto a lo socialmente establecido, que en Facebook puede leerse en los ítems sobre estudio, trabajo y "estado sentimental”. Las estrategias que utilizan para socializar mediante Facebook -articulando el backstage y el front de su perfil- indican que su construcción identitaria es un proceso regulado que implica performances de intimi$\mathrm{dad}$, alejados del prejuicio social que muchas veces recae sobre ellos en cuanto hacen una exhibición desmesurada y sin controles. Por último, se espera que este recorrido descriptivo-analítico permita sentar las bases para futuros trabajos sobre este emergente campo de estudios.

\section{Referencias}

Boyd, D. (2014). It's Complicated. The Social Lives of Networked teens. London: Yale University Press.

Boyd, D. (2008). Why Youth Love Social Network Sites: The Role of Networked Publics in Teenage Social Life. En D. Buckingham (Ed.), Youth, Media and Digital Media. Cambridge: The MIT Press.

Boyd, D., \& Ellison, N. (2007). Social Network Sites: definition, History and Scholarship. Journal of Computer-Mediated Communication, 13, 210-230. 
Farquhar, L. (2009). Identity Negotiation on Facebook.com (Tesis doctoral inedita). University of Iowa, United State.

Goffman, E. (1959). The presentation of self in everyday life. NY: Anchor Books.

Internet World Stats. (10 Septiembre 2014). Facebook users in the world. Recuperado de http://goo.gl/95LCl

Linne, J. (2014). Usos comunes de Facebook en adolescentes de distintos sectores sociales. Comunicar, 43, 189-197. doi: 10.3916/C43-2014-19.

López, G., \& Ciuffoli, C. (2012). Facebook es el mensaje. Oralidad, escritura y después. Buenos Aires: La Crujía.

Pedroni, M., Pasquali, F., \& Carlo, S. (2014). My Friends are my Audience: Mass-mediation of Personal Content and Relations in Facebook. Observatorio $\left(O B S^{*}\right)$, 8(3), 97-113.

Prensky, M. (2001). Digital natives, digital inmigrants. On the Horizon, 9(5), 1-6.
Sistema de Información Cultural de la Argentina. (2014). Encuesta Nacional de Consumos culturales. Recuperado de http://goo.gl/rMpB4n

Urresti, M. (2012). Las cuatro pantallas y las generaciones jóvenes. En A. Artopoulos (Coord.), La sociedad de las cuatro pantallas. Una mirada latinoamericana (pp. 3-29). Buenos Aires: Ariel.

Urresti, M. (2008). Ciberculturas juveniles: vida cotidiana, subjetividad y pertenencia entre los jóvenes ante el impacto de las nuevas tecnologías de la comunicación y la información. En: M. URRESTI, (Ed.), Ciberculturas juveniles (pp. 13-66). Buenos Aires: La Crujía.

Van Dijk, J. (2013). You have one identity. Performing the self on Facebook and LinkedIn. Media, Culture \& Society, 35(8), 199-215. 